\title{
Team Teaching with Overseas Partners in the Days of the "New Normal": A Better Way to Introduce Innovation and Build Local Expertise
}

\author{
Ania Lian
}

\author{
Charles Darwin University, Australia \\ *Email: Ania.Lian@cdu.edu.au
}

\begin{abstract}
The gap in the quality-of-service delivery in the education sector between the developed and developing countries of Southeast Asia continues to grow as the new accountability structures introduced globally are not straightforward, and scholars in Southeast Asia lack research capital to draw on and decades of experience to translate the new policies into practice. The use of technology also presents numerous challenges as CALL (Computer-Assisted Language-Learning) literature too frequently reduces technology to a communication platform or behaviouristic drills, with scholarly imagination being stifled by both our intellectual frameworks and experience. This paper reports on three research projects conducted in Southeast Asia, which sought to counter the abovementioned obstacles. The paper illustrates the context of these projects, how technology was used to support students' learning and includes suggestions for improvement.
\end{abstract}

Keywords: CALL, online learning and teaching, TESOL, innovation in CALL and English literacy.

\section{INTRODUCTION}

As accountability structures evolve globally, every educational institution strives to build the capacity of its team to offer learning experiences that comply with the modern requirements for education to build the academic, social, and emotional capacities of their graduates. However, change is often slow as it takes time to embrace new concepts and adapt them to one's context. Furthermore, not all concepts immediately imply forms of practice that engender transformative learning experiences embedded in values, such as humanization, localization, regionalization, and universalization [1], which typify all modern curricula. For example, in Cambodia, as illustrated by Lor [2], higher education institutions rewrote their courses and curricula, yet publications reporting on the integration of the new international standards fail to make explicit links to those standards, let alone explain the processes that they entail. The study by Doung Dara [ 3$]$ is a case in point. It investigated reading comprehension problems of Cambodian high school students of
English. Around 233 students participated in the study and six English teachers from two high schools in Kep province.

The students in Dara's [ $\underline{3}$ ] study believed that they did not understand texts because they had "complex grammar, difficult vocabulary, technical words and sentence structure" [ㄱ, p. 54]. They also blamed teachers for bad pedagogy (p. 54), while teachers pointed to large class sizes and poor students' language skills who seemed not ready for high school curricula. The study by Dara is representative of many EFL scholars, where the publication revolves around an issue that is neither theorized nor related to the national curriculum of Cambodia [4]. In Dara's (p. 52) discussion of research on reading, reading involves skillful management of a multiplicity of relationships involving linguistic competence (language structures), cognitive capacity (memory), psychological factors (anxiety) and social factors (motivation). Dara's research summarises a lot of insights on reading yet does not explain what it 
involves from the perspective of the national curriculum of Cambodia.

As Lian and Norman [5] explain, Texts are information recorded for communication, and reading is an act of interaction with this information. Framed in this way, the act of reading locates the reader in the community and reading is seen as participation in the community's conversations while utilizing available text technologies. Reading has a transformative impact on readers as it expands one's access to community capital while, at the same time, shaping one's understanding of its power. So reading is not just comprehension of words organized by grammar interrupted by psychological attributes or factors: it is engagement for a purpose. It is beyond the scope of this paper to expand on this topic, but reflections of this kind are necessary by authors when discussing reading especially considering that the national curriculum of Cambodia is interested in activities that build students' capacity to participate in the society, not in outcomes that divorce learning from students' lives and therefore the contexts that give their learning both meaning and relevance.

The concept of reading as transformative participation echoes the agentive role that the new national curriculum of Cambodia [4] attributes to students, a connection that Dara [3] failed to make. The national curriculum locates students in the community, both local and broader, and focuses educators on forms of participation that support citizen empowerment. Central to this goal is the idea of learning through and for participation. However, as indicated earlier, this link between learning and participation presents a challenge. The recent study by Keuk and Monh [6] also failed to create this link. The study sought to investigate the impact of reflective teaching on pre-service teachers. While an important objective, the study made no mention of the policy documents against which pre-service teachers were to evaluate their performance or the performance of their peers. No mention was made of the national curriculum or Teacher Professional Standards [7]. This tendency to "forget" these important documents may be largely due to the tendency of the field of Teaching English to Speakers of Other Languages (TESOL) to draw largely on the literature of the field, much less on internal policy documents. Indeed, in their study, Keuk and Monh did refer to Joyce and Shower [8] and their model of what constitutes pedagogic knowledge. However, without the reference to the national policy, the study was not able to critically assess the model that they used and its relevance or sufficiency for pre-service teachers.
Integration of the national policies when teaching English in schools or preparing future teachers is also a challenge in other Southeast Asian countries. As indicated by Sudimantara [9], the currently mandated approaches to literacy in Indonesia once again focus more on skills and content than the students' life experiences and contexts. When analyzing the genre approach as described in a study by Cahyono [10], Sudimantara (p. 50) demonstrated the passive role of the students and the didactic, top-down method of the approach. Students are taught genre as if the explanations of the teacher warranted quality of students' text production and comprehension, not the relationship that students themselves construct between the text and its place among other texts and conversations that comprise students' histories and sources of knowledge. In the genre approach, as Sudimantara explains, the teacher models, analyses, explains, highlights produces examples. Students are expected to relate to these explanations, although the approach itself is not proposing evidence that would justify this expectation.

This reliance on the explicit teaching of content is a legacy of the 20th century teaching models that persist as the field of education refuses to examine its past defeats and shortcomings and remains caught up in its traditional dichotomies of explicit/implicit learning as if these polarities captured the entirety of the learning process and there was no space inbetween to explore and take advantage of. Scholars in CALL also get caught in these discourses, and CALL is seen mainly as games and various Web tools, such as dictionaries, Google maps, blogs, wikis, chat rooms, Skype or Moodle, etc., for teachers to elicit learning based on the vague and outdated hypotheses of the Second Language Acquisition field. (Notably, Google Translate is given very little attention.) Following this line of thinking, Gebhard, Shin and Seger [11], Blin and Appel [12], Gonzalez-Lloret [13], and Reinhardt and Zander [14] suggest using digital technology as a communication-mediating device rather than as a tool with qualities that can be utilized for assisting learning. This approach to technology undervalues the potential that CALL and the context of second language teaching hold for understanding the process of second language learning and education.

This article briefly describes three research projects, which sought to counter the obstacles identified above, which typically slow down change and short-change the promises of the new education reforms. Two of these projects took place in different universities in Indonesia, and the third project is currently underway in Cambodia. The discussion will 
illustrate the context of these projects, how technology was used to support team teaching with international partners and how the "new normal" was more helpful in this venture rather than a problem. The research findings from the two already completed projects provide strong evidence that the model was a success and was superior to the genre approach against which the two projects were compared and tested. The study findings suggest that collaborations with international partners can benefit from more "hands-on" methods of work. These types of collaboration are likely to both progress innovation faster and enable a better understanding by each group of their contexts, challenges, and possibilities.

\section{TEACHING ACADEMIC WRITING WITH CALL}

Two studies in Indonesia were conducted [9, 16] with Year 2 students, each aiming to support students in developing their academic writing skills. The study by Sudimantara [9] has already been published, while the work by Baehaqi [16] still awaits publication. Both projects were similar. However, while Sudimantara taught in a mixed-method mode, online and face-to-face, Baehaqi taught online only as the situation in Indonesia did not allow for face-to-face meetings. Both studies were couched in the principle of transformative learning, with students engaged in tasks that connected their study with their social and personal lives and both engaged students in reflecting on their learning experiences and their transfer to their future jobs as language teachers. Both studies made explicit links to the National Higher Education Standards updated and released in 2020 [15], providing learning experiences that were interactive, holistic, integrative, scientific, contextual, thematic, effective, collaborative, and student-centered. While the detailed description of the context of these two similar studies can be found in Sudimantara [9], this section focuses on the tools of CALL and their role in supporting transformative learning.

\subsection{Pronunciation for building fluency and listening skills}

It has been long recognized [17] that writing and intonation systems are linked together as intonation bootstraps the flow of sentences in text. Students in Sudimantara [9] and Baehaqi [16] studies were given access to pronunciation exercises developed by Professor Andrew Lian and researched in a multitude of studies, recently by Lian, Cai, Chen, Ou, Zheng [18]. These exercises comprised students' homework; however, to build students' confidence in their use, Sudimantara integrated these activities at the start of some of his face-to-face classes. The verbotonal approach [19, 20] was used as the method used to elicit change in the students' perception of English intonation and sounds used. As Sudimantara (p. 67) explains:

[T]he approach utilizes low-pass filtering of auditory stimuli. The technique involves modifying recorded audio using an audio filter that only allows frequencies under $320 \mathrm{~Hz}$ (or some other appropriate frequency) to be preserved. According to Lian et al (p. 4608), "this filtered stimulus preserves the fundamental frequency (F0) of the sentences being studied, together with their stress, rhythm, loudness and intonation features, while the higher frequencies that help to define words are removed". ... What remains, after the audio was filtered, is "a stream of sound reminiscent of a hummed sentence, where the prosody becomes salient and available in a way that is unusual, stimulating, and awareness-raising" (Lian et al, 2020, pp. 4608-9). Because the remaining sound is novel and unfamiliar, "this stimulation, arguably, is capable of heightening listeners' awareness to the prosodic features of the language being studied while, simultaneously, lightening the processing load" (p. 4609). This assumption is aligned with the "orienting reflex" concept, first conceptualised by Russian scientists and summarised by Peterson (2018). As Lian et al explain, this load reduction occurs because "the listener is free from processing words and meanings, thus releasing more attentional resources for increased processing of the prosodic patterns themselves or for engaging in other cerebral activity". The study by Lian et al. (2020) provided brain images that indicate that this is what actually happens: the filtered signal, especially when heard through the left ear, showed to be processed in the right hemisphere, exactly where Ramachandran (1996) proposed that learning takes place. The study was the first one to examine how ESL (EFL) learners process audio, and it opens a new area of investigation for L2 research.

The key principle of the method of Verbotonalism is load reduction. However, unlike the Interaction Hypothesis of Long [21], Verbotonalism makes use of Ramachandran's [22] hypothesis, developed in the context of research with patients with paralyzed brains, that stipulates differences in the ways in which, typically, the human brain process information. 


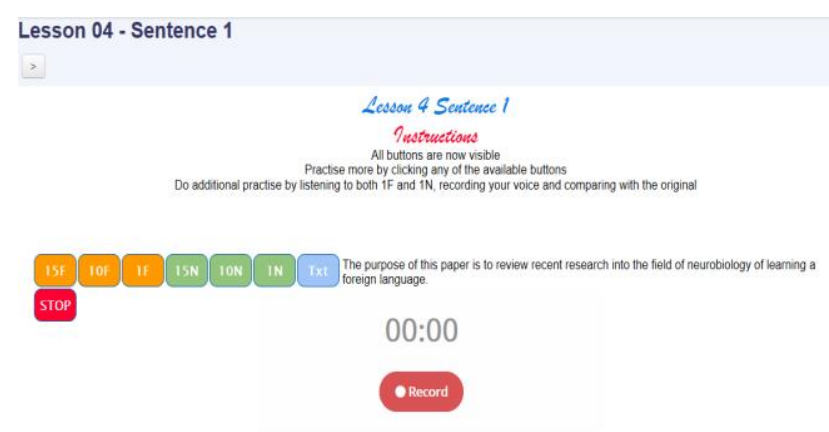

Figure 1. An example of a Moodle lesson based on verbotonal theory $[\underline{19}, \underline{20}]$

Other tools described below are based on this hypothesis but draw on different holistic systems to stimulate hypothesis-building in the right hemisphere and to bypass, as much as possible, the left hemisphere, which is hypothesized to interfere with learning as it provides the learner with its expert information while, in fact, there is a need for change. All tools target different modalities, and the approach that is described here is referred to as utilizing multisensory strategies of load reduction.

\subsection{Reading for Emotion}

The model was developed first by Ania Lian [23] and was subsequently further developed in the context of these studies and also to support undergraduate pre-service teachers of literacy taught by Ania Lian. As described by Sudimantara [9, p. 69]:

The model draws on studies by Damasio and Immordino-Yang (2007), and Immordino-Yang (2009) that provide evidence that emotions are the most fundamental processes that humans utilize to make sense of the world. Emotions are the key mechanisms that structure our experiences, "I feel therefore I am" (Damasio, 1995). Lian (2017, p. 6) concluded that it is not vocabulary or grammar that students need to "comprehend", but the emotional significance of the structures, "the ways in which emotions are turned into a text to evoke a desired effect in the interlocutors". She suggested that attention to emotions enables students to engage with texts from the perspective of their personal experiences, analyze texts by comparing and contrasting what they see in texts and why from the perspective of emotions. No specific structures are the students provided with, no explicit teaching happens, but, nonetheless, the students make explicit to themselves what they see in texts, why and how and what this means to them from the perspective of academic writing. In this way, the learning process can be said to be "explicit", but not the teaching process.

Understandings that students form during the process of text analysis are compared with the stages of the text that Ania Lian [23] developed to stimulate analysis. Several strategies were being used to elicit students' reflection, and the study by Baehaqi [16] utilized a greater range of techniques as it took place after the study by Sudimantara [9] was already completed. Since the method was new and the researchers had little experience in stimulating students' reflective discussions and comparisons, the two research studies used a pre-recorded video, with Ania Lian leading the reflective process and the teachers stopping the video in places where students were to engage in discussions on text analysis. Interestingly, the video podcasts did not work with academic texts but largely with fables before examining academic abstracts or scientific reports. In other words, it is not the academic genre that was being taught. Instead, knowing how to write argumentative and academic texts was to be the outcome that was to emerge from an array of activities that engaged students in reflecting on how texts manipulate emotions to affect the desired objective. Useful lists identifying positive and negative emotions can be found using Google Search. 


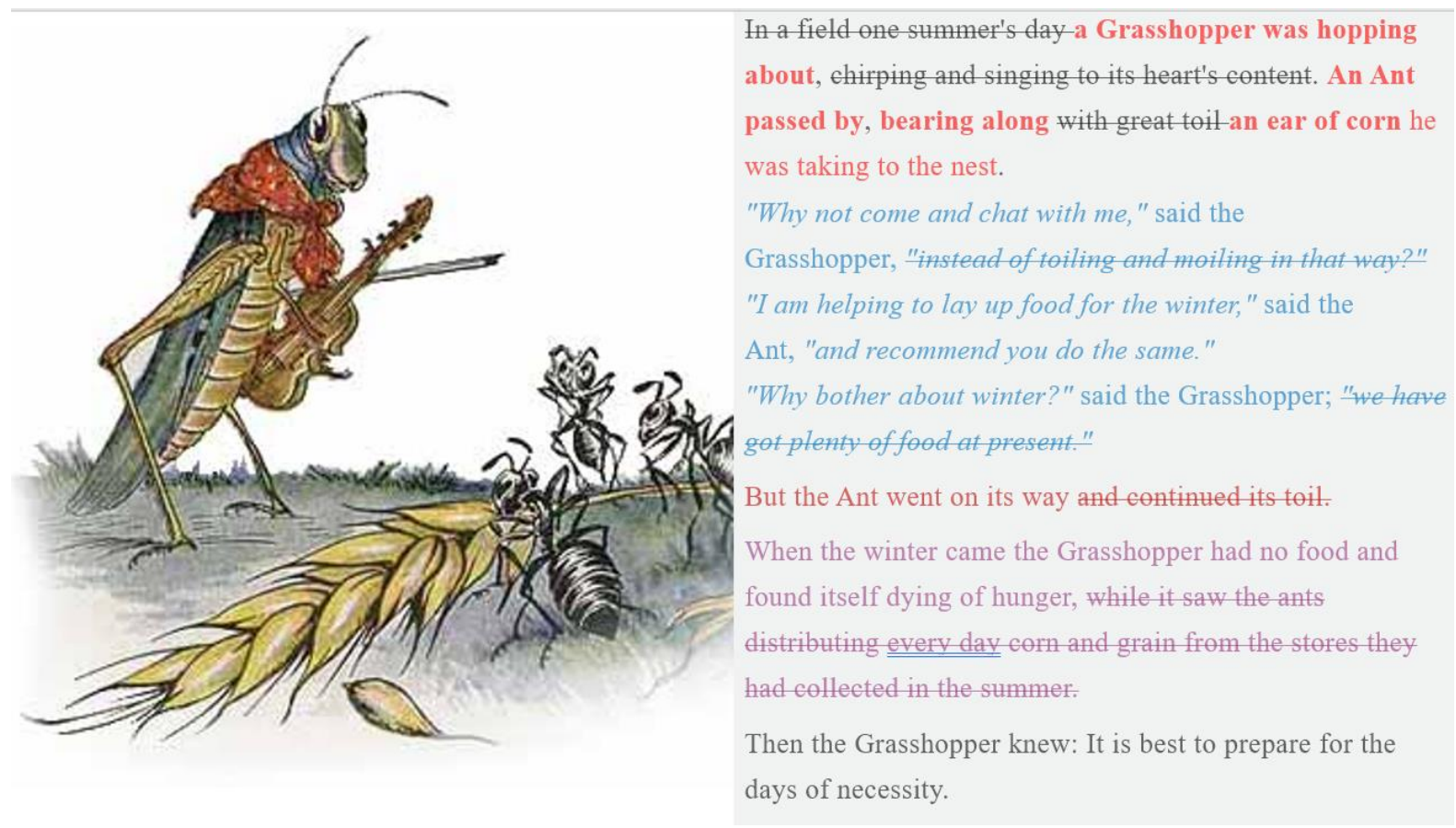

Figure 2: Learning academic writing with fables.

Some of the strategies that were used involved students in identifying lines in the text that, once deleted, did not violate the grammatical correctness of the text. Students were then analyzing the emotional power of the deletions, which became apparent once the text was removed. Figure $\underline{2}$ in illustrates this strategy. Also, students examined how texts were sequenced and how authors played with text sequences for greater impact. This was visible especially in scientific reports written for the broader public, where authors used the "moral" of their report and inserted it right under the abstract (brief summary) of their report, not at the end of the report, in order to attract readers' attention and signal that the text will be provoking and interesting. The canonical structure of all texts is summarised in Figure $\underline{3}$ (Appendix). In Sudimantara's [9] study, students also analyzed professionally written abstracts by scholars and examined if they were well constructed and how they could be improved. Students also used their analyses and, using Ramachandran and Hirstein's [24] neurological theory of aesthetic experience, learned how to analyze texts in terms of aesthetics. Figure $\underline{4}$ in the Appendix illustrates an example. Students used qualities such as grouping, contrast, isolation, symmetry, perceptual problem-solving, and metaphor. This analysis was useful to assist students in learning how to create a summary of texts to make evident what they were about and how arguments were constructed. Figure $\underline{5}$ illustrates one such summary.

\subsection{The neurological theory of aesthetic experience}

There are many ways in which Ramachandran and Hirstein's [24] neurological theory of aesthetic experience can be utilized. One such way was described by Lian, Bodnarchuk, Lian and Napiza [17]. In the two studies, the method described by Lian et was applied, with students recording sentences from their texts to analyze the intonation graphs from the perspective of aesthetics. As Sudimantara [9, p. 102] writes:

[...] learners of academic writing in the experiment could revise their own texts as, including word order and punctuation [without ever being taught these as grammatical points]. Word order follows the intonation curve, as indicated by Lian et al. (2017). When the intonation is interrupted, this typically occurs when a subordinated clause is inserted or when words are inserted specifically to break the flow of order. Word order is dictated tightly by the flow of the intonation. To record their voices, the students used PRAAT, Winpitch, or Speech Analyzer 3.1. These three tools were downloadable for free, but Speech Analyzer and PRAAT seemed more user-friendly. 
Once again, Ania Lian's video podcast demonstrated how intonation patterns could be analyzed and the impact of any violations on aesthetic experience. Figure $\underline{6}$ in the Appendix displays the intonation pattern of a chunk of the first sentence from an article by Andrew Lian and Roland Sussex [25]. Analysis shows that academic texts have long sentences, typically with the same amount of chunks (intonational group), to communicate sufficient complexity for the listener or reader to be provided with enough information to assist their comprehension (problem-solve). On the other hand, students' intonation patterns tend to be irregular, and the intonation does not always show a falling pattern, typical of English, where the most important information tends to be right at the start of the sentence. A more detailed explanation is provided in Lian et al. [17].

Students in Sudimantara [9] and Behaqi's [16] studies worked with the tools described above, relied to a great extent on pre-prepared podcasts to ensure that the intentions of the pedagogy described above were not compromised and that students built their understandings based on their experiences and what they knew about texts. In Behaqi's study, students' knowledge of Bahasa Indonesia was integrated, with students comparing their English text productions with their home language. Google Translate was encouraged to facilitate such comparisons and teach students how to make the most from Google Translate. In both studies, students were involved in writing chapters for a book on their experiences in learning English. Figure 7 in the Appendix illustrates the assessment tasks from Sudimantara.

Already the team that mentored the studies described above and scholars from Cambodia are engaged in a project in Cambodia utilizing the CALL tools described above. A website was created to consolidate all the learning tools and pre-recorded video podcasts as well as the link to Moodle with pronunciation exercises. Students in Cambodia were also given some game-like exercises, taken from Scootle - an Australian website with educational resources- to diversify their activities and have a chance to attend to issues that, possibly, are not addressed by the tools described in this paper. Figure $\underline{8}$ illustrates the website. Figure $\underline{9}$ identifies the assessment tasks of the experimental group in this study.

\section{FINDINGS}

Tables $\underline{1}$ and $\underline{2}$ in the Appendix illustrate the findings from Sudimantara's [9] study, and Figure 10 shows the preliminary findings of Baehaqi's [16] study. As described by Sudimantara,

A double-blind rating procedure was applied. This is the first study that applied a double-blind rating to the genre approach and its alternative. Control and experimental groups were created, 122 students took part in the study. The results showed that the multi-sensory model used with the experimental group resulted in significantly improved academic writing performance. There was a substantial amount of progress in the experimental group's performance. It caught up the initial difference in scores on the pretest and accelerated past the control group. Further, the relatively small standard deviation in both pretest and posttest remained constant, indicating that the group improved as a whole, while $54.41 \%$ of the control group obtained either lower or equal scores to those obtained in the pretest. Implications of the study for research and teacher education were presented and discussed.

Baehaqi's [16] study is yet to be finalized and published; however, the preliminary findings point again to the advantage of the multi-sensory strategies of load reduction. As illustrated in Figure 10, the control and experimental groups were equal on pretest but diverged dramatically on the post-test, with the experimental group outperforming the control group. Both Sudimantara's [9] and Baehaqi's studies were double-blind, which meant that the raters assessing students' performance on academic writing did not know what group they were assessing and whether it was a pre-test or post-test assignment. When combined with results of several studies conducted under the mentorship of Andrew Lian [18], these findings demonstrate that these are not "orphan results" but an increasingly strong argument for the multi-sensory load reduction approach.

\section{IMPLICATIONS}

The leading concerns that underpinned the studies described in this paper were (a) the slow integration of education policies in Southeast Asia specifically, and (b) the outdated frameworks that are currently used in many institutions that in the past were ground-breaking but that no longer withstand the test of time. The understanding of transformative learning presented in this paper places the student at the centre and relates the students to their more and less immediate contexts of participation in their societies. The objective of this paper was to describe the motivations behind the design of the CALL tools 
used in the research studies discussed. In each study, students were engaged in tasks to engage and communicate their experiences to a broader audience. Pre-test and post-test assessment tasks were different and were not assessed. As illustrated, to ensure that the objectives that motivated the studies were implemented as best as possible, the study utilized ready-made tools and also engaged expert collaborators to lead class activities, whether using ZOOM or in face-to-face settings. This strategy opened a new way for collaborating with scholars and students nationally and internationally, where experts are part of the teaching team. This proved to be successful as students quickly accommodated the presence of the external person and his or her voice. This strategy holds potentially a long-term promise as what happens in class is no longer dependent on the teacher, who may have a varied competence or confidence in using a new approach. Now, external experts can assist with the local teacher stopping the video and assisting students in focusing on the task introduced by the collaborating expert. In due course, local teachers and lecturers can suggest changes based on their experience and create their own video

\section{REFERENCES}

[1] T. Ogisu, "It is not politically correct: exploring tensions in developing student-centred policy in Cambodia," Compare: A journal of comparative and international education vol. 48 no. 5. pp. 768784. DOI: 10.1080/03057925.2017.1353409.

[2] T. Lor, Building community capacity in Cambodia using a community-based participatory approach: A case study in education. 2021, PhD Thesis. Charles Darwin University.

[3] D. Dara, "Investigating English Reading Comprehension Problems of Cambodian High School Students." American International Journal of Social Science vol. 8, no. 3, pp. 52-56. DOI:10.30845/aijss.

[4] Kingdom of Cambodia. Curriculum framework of general education and technical education, 2015, [Online]. Available: https://drive.google.com/file/d/0B1ekqZE5ZIUJY0 FoY25EZzZRSWM/view.

[5] A.B. Lian and A. Norman, A dialogic, evidencebased framework for integrating technology into school curricula. In Lian, A.B. Kell, P., Black, P. \& Koo Yew Lie (2017). Challenges in global podcasts and share them with other teachers and lecturers. The pre-record podcasts can be recycled in other projects and settings, effectively creating a national and regional pool of resources for teaching and learning a foreign language.

learning: Dealing with education issues from an international perspective, pp. 314-349, 2017.

[6] N. Keuk, and S. Monh, Reflective Practice for Preservice Teachers: A Case Study at the Institute of Foreign Languages. 2021. MoEYS Education Research Council.

[7] Ministry of Education, Youth, and Sport of Cambodia. (MoEYS), Continuous Professional Development Framework for Teachers and School Directors, 2019, [Online]. Available: http://www.unesco.org/new/fileadmin/MULTIME DIA/FIELD/Phnom_Penh/pdf/MoEYS_CPD_Fra mework_FD06_AJ_140919_en_clean.pdf.

[8] B. Joyce and B. Showers, Student achievement through staff development, Alexandria: VA: Association for Supervision and Curriculum Development.

[9] L.B. Sudimantara, Teaching academic writing in undergraduate English teacher education programs in Indonesia in the era of globalisation and cultural plurality, PhD Thesis. Charles Darwin University.

[10] S. P. Cahyono, Teaching L2 writing through the use of systemic functional linguistics (SFL). Indonesian Journal of English language teaching, vol. 13, no. 1, pp. 53-72, 2018. 
[11] M. Gebhard, D. Shin, and W. Seger, Blogging, systemic functional linguistics, and L2 academic literacies in an urban elementary school. CALICO Journal, vol. 28, no. 2, pp. 278-307, 2011.

[12] F. Blin and C. Appel, Computer-supported collaborative writing in practice: An activity theoretical study. CALICO Journal, vol. 28. no. 2, pp. 473-497. DOI: 10.11139/cj.28.2.473-497, 2011.

[13] M. Gonzalez-Lloret, Conversation analysis of Computer-Mediated Communication. CALICO Journal, vol. 28, no. 2, pp. 308-325, 2011.

[14] J. Reinhardt and V. Zander, Social networking in an Intensive English Program classroom: A language socialization perspective. CALICO Journal, vol. 28, no. 2, pp. 326-345, 2011.

[15] Ministry of Research Technology and Higher Education (MORTHE). Decree No.44 Year 2015 on National Higher Education Standards. Jakarta, 2015.

[16] L. Behaeqi, Study of 2nd Year ELTE students in Indonesia in COVID-19 era through online teaching. $\mathrm{PhD}$ project preliminary results. Charles Darwin University.

[17] A.B. Lian, A. Bodnarchuk, A-P. Lian, and C. Napiza, Academic writing as aesthetics applied: Creative Use of Technology to Support Multisensory Learning. In: A.B. Lian, P. Kell, P. Black and K.Y. Lie, Challenges in Global Learning, pp. 350-374, 2017. London: Cambridge Scholars Publishing

[18] A-P. Lian, X. Cai, H. Chen, J. Ou and W. Zheng, Cerebral lateralization induced by dichotic listening to filtered and unfiltered stimuli: optimizing auditory input for foreign language learners. Journal of Critical Reviews, vol. 7. no. 19, pp. 4608-4625, 2020.

[19] P. Guberina, P., Restricted bands of frequencies in auditory rehabilitation of deaf. Zagreb: Institute of
Phonetics, Faculty of Arts, University of Zagreb, 1972.

[20] A-P. Lian, A-P., Intonation patterns of French. 1980. Melbourne : River Seine Publications, 1980

[21] M.H. Long, The role of the linguistic environment in second language acquisition. In W. C. Ritchie \& T. K, Bhatia (eds), Handbook of second language acquisition, pp. 413-468, 1996. New York: Academic Press.

[22] V.S. Ramachandran, V.S., The evolutionary biology of self-deception, laughter, dreaming and depression: Some clues from anosognosia. Medical Hypotheses, vol. 47, no. 5, pp. 347-362, 1996. DOI: https://doi.org/10.1016/S03069877(96)90215-7.

[23] A.B. Lian, Reading for emotion with ICT tools. In W. Chen, et al. (Eds.) Proceedings of the 25th International Conference on Computers in Education. (Internationally refereed proceedings), 2017. New Zealand: Asia-Pacific Society for Computers in Education.

[24] V.S. Ramachandran and W. Hirstein, The science of art: A neurological theory of aesthetic experience. Journal of Consciousness Studies, vol. 6, no. 6-7, pp. 15-51, 1999.

[25] A-P. Lian, A.-P. and R. Sussex, Toward a critical epistemology for learning languages and cultures in 21st century Asia. In Andy Curtis and Roland Sussex (Eds), Intercultural communication in Asia: Education, language and values, 2018. Proceedings of the Third Macao International Forum, 15-19 December 2014, Macao Polytechnic Institute, Macao. Berlin and London: Springer Verlag. 


\section{APPENDIX}

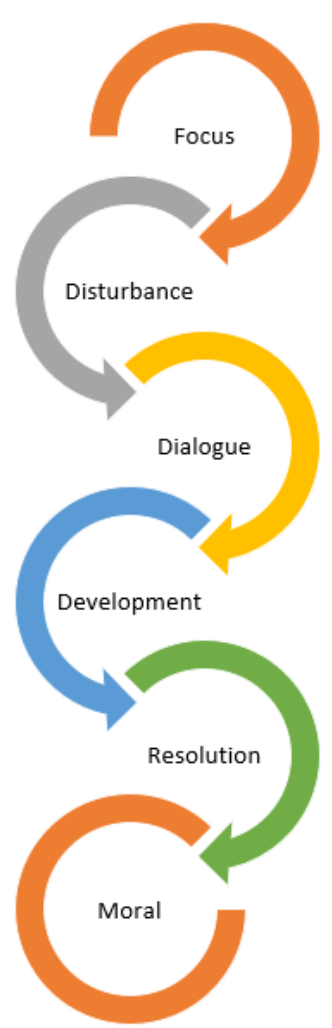

Figure 3: The canonical structure of all texts as proposed by Ania Lian [21]: Focus, Disturbance, Dialogue, Development, Resolution, and Moral. Sequence developed for pedagogical purposes.

\footnotetext{
In a field one summer's day a Grasshopper was hopping about, chirping and singing to its heart's content. An Ant passed by, bearing along with great toil-an ear of corn he was taking to the nest.

"Why not come and chat with me," said the Grasshopper, "instead of toiling and moiling in that way?"

"I am helping to lay up food for the winter," said the Ant, "and recommend you do the same."

"Why bother about winter?" said the Grasshopper; "we have got plenty of food at present."

But the Ant went on its way and continued its toil.

When the winter came the Grasshopper had no food and found itself dying of hunger, while it saw the ants distributing every day corn and grain from the stores they had collected in the summer.

Then the Grasshopper knew: It is best to prepare for the days of necessity.

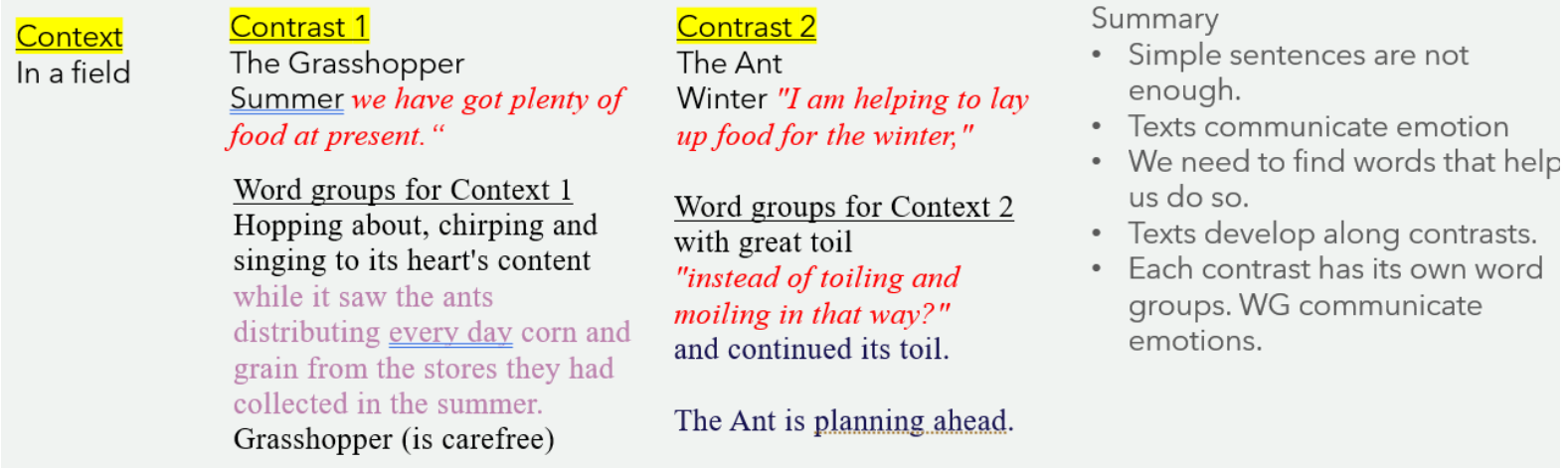

Figure 4. Applying Ramachandran and Hirstein's (1999) neurological theory of aesthetic experience while analysing fables. 


\section{Summary of the fable}

The fable was about what happens when we do not plan ahead.

To demonstrate this, the storyteller contrasted two insects, the carefree Grasshopper and the hard working Ant.

During summer, the Grasshopper was hopping about, chirping and singing to its heart's content, and wanted to chat with the Ant and distract it.

But the Ant was working hard, laying up food for the winter, and recommended that the Grasshopper does the same.

When winter came, the Grasshopper understood why the Ant was right. Hungry, he watched the ants distributing the supplies which they had collected over the summer.

This is how the Grasshopper understood, it is best to be prepared.

Figure 5. Learning to synthesise/summarise texts.

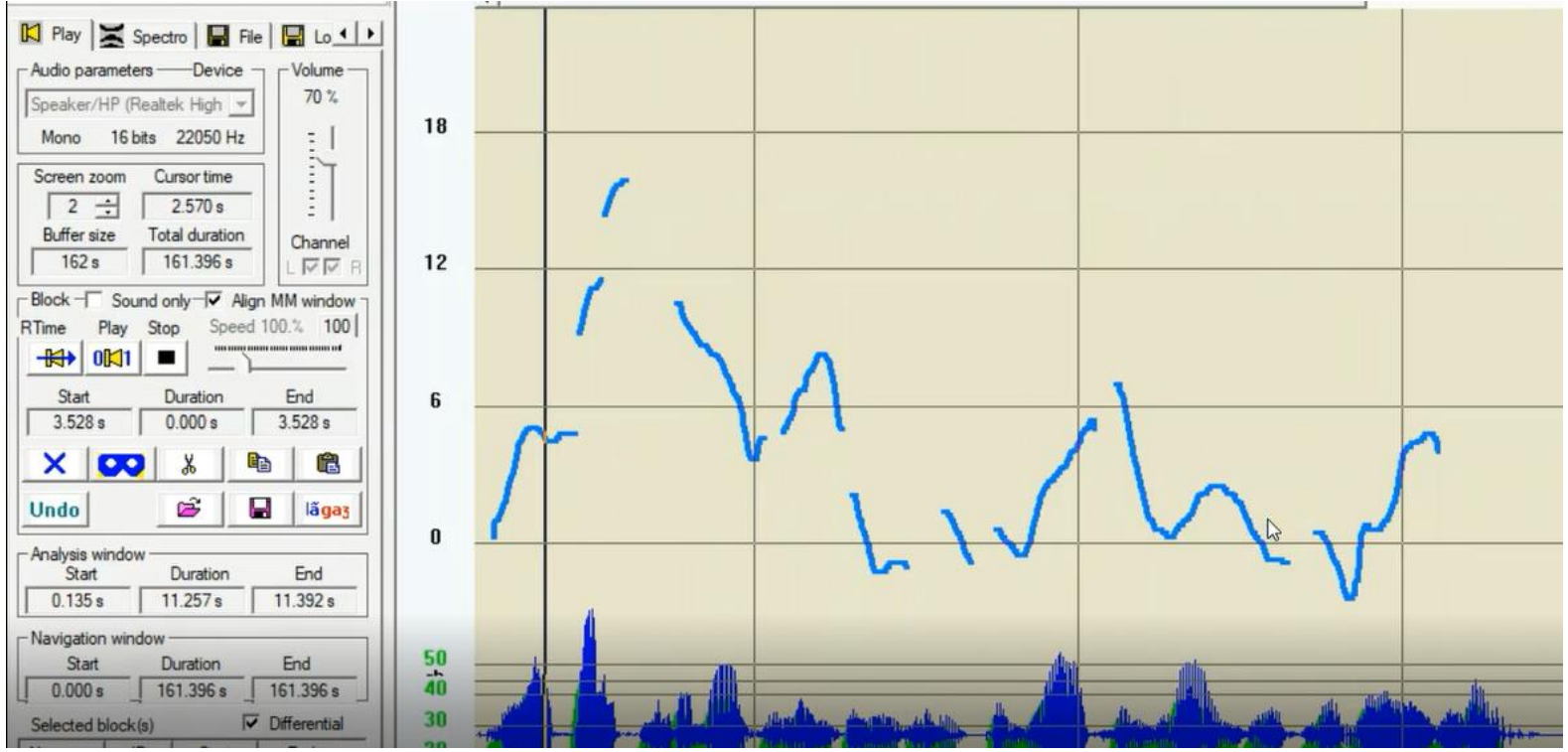

Figure 6. A chunk of an intonation graph produced using Winptich software (Developer: Professor Philippe Martin). 


\begin{tabular}{|c|c|c|c|c|}
\hline & Due Date & $\%$ & Task & $\begin{array}{l}\text { Demonstrated Learning } \\
\text { Outcomes }\end{array}$ \\
\hline Assignment 1 & WEEK 6 & $20 \%$ & $\begin{array}{l}\text { Students are requested to } \\
\text { submit a general structure } \\
\text { of their chapter, including } \\
\text { the abstract and a } \\
\text { preliminary list of } \\
\text { references. }\end{array}$ & $\begin{array}{l}\text { - Understanding the } \\
\text { difference between academic } \\
\text { and other genres of writing. } \\
\text { - Capacity to plan academic } \\
\text { texts. }\end{array}$ \\
\hline Assignment 2 & WEEK 10 & $20 \%$ & $\begin{array}{l}\text { Students are requested to } \\
\text { submit the first full draft of } \\
\text { their chapter. Specific } \\
\text { attention needs to be paid } \\
\text { to text coherence and } \\
\text { critical analysis. }\end{array}$ & $\begin{array}{l}\text { - Demonstrated clarity in } \\
\text { writing } \\
\text { - Demonstrated capacity to } \\
\text { approach academic texts } \\
\text { critically }\end{array}$ \\
\hline Assignment 3 & WEEK 16 & $60 \%$ & $\begin{array}{l}\text { Students are requested to } \\
\text { submit the final draft of the } \\
\text { chapter. Chapters should } \\
\text { reflect creative approach to } \\
\text { writing, systematic } \\
\text { argumentation and clarity of } \\
\text { expression. }\end{array}$ & $\begin{array}{l}\text { - Expressing creativity in } \\
\text { academic writing } \\
\text { - Demonstrated capacity to } \\
\text { integrate and organise } \\
\text { information systematically, } \\
\text { - Identifying, understanding } \\
\text { and applying linguistic } \\
\text { structures in order to make } \\
\text { academic writing meaningful. }\end{array}$ \\
\hline
\end{tabular}

Figure 7: Assessment tasks from Sudimantara's study.

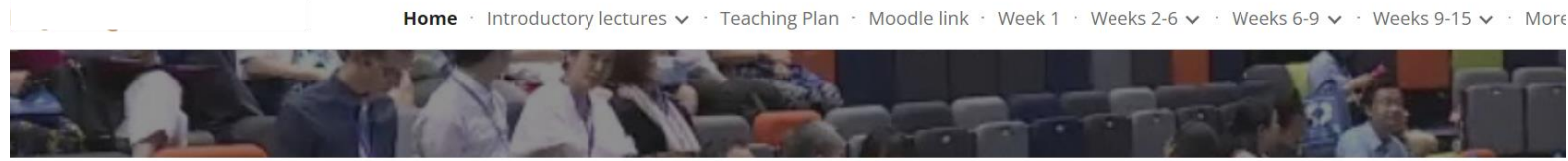

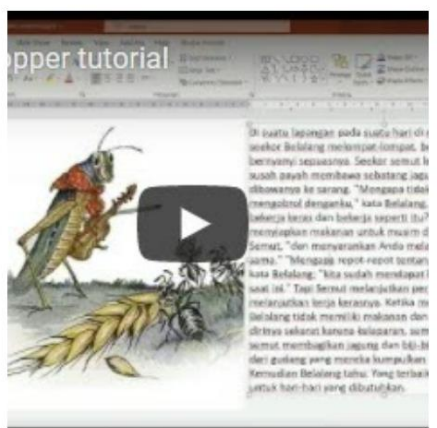

From fables to scientific reports: building comprehension writing and analytical skills
Click here for Professor Andrew Lian's introductory lecture

Click here for a video introducing the course by Dr Ania Lian.

The national curriculum of Cambodia (Kingdom of Cambodia, 2015) concerns itself with the development of students' lifelong learning capacities and values, such as humanisation, localisation, regionalisation, and universalisation. It presents individuals as situated and able to consider the local and global factors that impact on the human condition. The activities of this Teaching Plan and its assessment components target those skills and values, enabling students to understand that English language is a tool for (a) learning about the world, (b) communicating this knowledge using modern tools of communication, such as ICT; and (c) bringing the acquired knowledge to their local community for the benefit of everyone. The teaching approach used in this project is learner-centred. Teachers offer activities that stimulate students' reflective engagement in their learning.

Figure 8: Website for learning English in Cambodia. 


\begin{tabular}{|c|c|c|}
\hline & Task & Demonstrated Learning Outcomes \\
\hline $\begin{array}{l}\text { Assignment } 1 \\
\text { Due: WEEK } 6 \\
\% 30 \% \\
\text { Minimum } \\
\text { words: } 600\end{array}$ & $\begin{array}{l}\text { Assignment } 1 \text { had two parts: } \\
\text { (1) Website design: Students will } \\
\text { submit a link to their group's } \\
\text { website. } \\
\text { (2) Creating a story for your website: } \\
\text { Each student will upload their } \\
\text { multimedia stories in English onto } \\
\text { their group's website. The story must } \\
\text { integrate text, pictures, and a video } \\
\text { with audio. The story must be } \\
\text { minimum } 700 \text { words long. }\end{array}$ & $\begin{array}{l}\text { 1. Work in groups to create a } \\
\text { publication site } \\
\text { 2. Utilise multimedia to enhance } \\
\text { creativity } \\
\text { 3. Understand and use genres } \\
\text { correctly } \\
\text { 4. Demonstrate clarity of texts. }\end{array}$ \\
\hline $\begin{array}{l}\text { Assignment } 2 \\
\text { Due: WEEK } 9 \\
\% 35 \% \\
\text { Minimum } \\
\text { words: } 500\end{array}$ & $\begin{array}{l}\text { Assignment } 2 \text { had two parts: } \\
\text { (1) Students design an advertisement } \\
\text { of the NIE: Students upload the } \\
\text { advertisement onto their group's } \\
\text { website. The ad must integrate text, } \\
\text { pictures, and a video with audio. It } \\
\text { must be at least } 500 \text { words long. } \\
\text { (2) Print version of the advertisement } \\
\text { is to be submitted separately using } \\
\text { Google Drive and the link included } \\
\text { on the website. }\end{array}$ & $\begin{array}{l}\text { 1. Work in groups to create a } \\
\text { publication site } \\
\text { 2. Utilise multimedia to enhance } \\
\text { creativity } \\
\text { 3. Understand and use genres } \\
\text { correctly } \\
\text { 4. Demonstrate clarity in writing } \\
\text { 5. Improve fluency of speech }\end{array}$ \\
\hline $\begin{array}{l}\text { Assignment } 3 \\
\text { Due: WEEK15 } \\
\% 35 \% \\
\text { Minimum } \\
\text { words: } 500\end{array}$ & $\begin{array}{l}\text { Assignment } 2 \text { has two parts: } \\
\text { (1) Students design a presentation on } \\
\text { any topic that they want to share with } \\
\text { their local Khmer community. They } \\
\text { design it first in English and upload } \\
\text { their presentation in the form of a } \\
\text { video onto their group's website. } \\
\text { Print versions of the presentations are } \\
\text { to be submitted separately using } \\
\text { Google Drive and the link included } \\
\text { on the website. } \\
\text { (2) Students are also required to } \\
\text { identify a local hub, where they will } \\
\text { give their presentations in Khmer to } \\
\text { their local community. Video } \\
\text { recorded presentations in Khmer are } \\
\text { to be uploaded onto the respective } \\
\text { group websites. Print versions of the } \\
\text { presentations in Khmer are to be } \\
\text { submitted separately using Google } \\
\text { Drive and the link included on the } \\
\text { wehsite }\end{array}$ & $\begin{array}{l}\text { 1. Work in groups to create a } \\
\text { publication site } \\
\text { 2. Utilise multimedia to enhance } \\
\text { creativity } \\
\text { 3. Understand and use genres } \\
\text { correctly } \\
\text { 4. Demonstrate clarity in writing } \\
\text { 5. Improve fluency of speech }\end{array}$ \\
\hline
\end{tabular}

Figure 9: Assessment tasks of students in the research study in Cambodia. 
Table 1: Between-group comparison for the pre-test in Sudimantara [9] study.

\begin{tabular}{llllll} 
& Group & N & Mean & SD & SE \\
\hline PRETEST & CTRL & 68 & 66.750 & 5.717 & 0.693 \\
& EXP & 54 & 61.948 & 4.817 & 0.655 \\
\hline
\end{tabular}

Difference of 4.803 in favour of the control group

Independent Samples T-Test

\begin{tabular}{lccccr}
\hline & Test & Statistic & df & p & Effect Size \\
\hline PRETEST & Student & 4.935 & 120 & $<.001^{*}$ & 0.900 \\
& & & & & \\
\hline
\end{tabular}

Table 2. Between-group comparison for the post-test in Sudimantara [9] study.

\section{Control Experimental}

\begin{tabular}{lrr}
\hline Valid & 68 & 54 \\
Mean & 67.745 & 73.137 \\
Std. Deviation & 8.967 & 5.079 \\
Minimum & 51.050 & 56.750 \\
Maximum & 87.490 & 83.290
\end{tabular}

POSTTEST

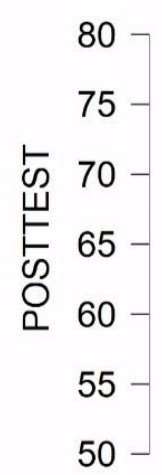
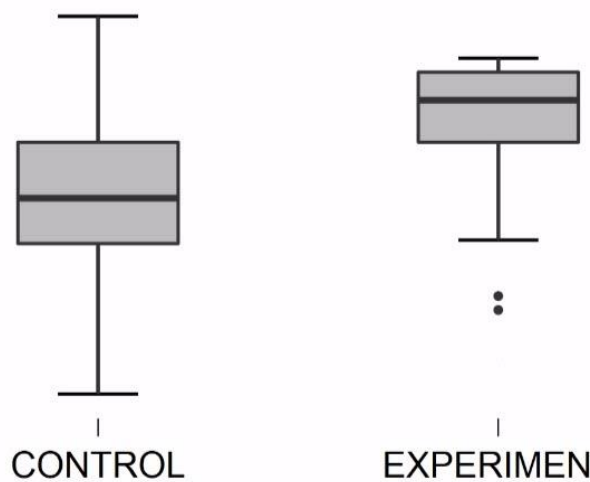

:

EXPERIMENT

\section{GROUPS}

Figure 10. Preliminary results of Baehaqi’s [16] study. 